\title{
EUROPE'S TERRITORIAL FUTURES BETWEEN DAYDREAMS AND NIGHTMARES
}

\author{
Kai Böhme, Christian Lüer \\ Spatial Foresight GmbH \\ 7, rue de Luxembourg, L-7330 Heisdorf: Luxembourg \\ kai.boehme@spatialforesight.eu, christian.lueer@spatialforesight.eu
}

\begin{abstract}
Europe is changing. The grand societal challenges which shape the European development have a considerable influence on our governance systems and the possible development paths in different parts of Europe, its regions and cities. Based on the results of the FP7 research project FLAGSHIP, this article discusses possible governance and territorial futures for Europe - constantly balancing between daydreams and nightmares. The end of this article contains a plea for shared territorial vision for Europe.
\end{abstract}

Keywords: forward looking analysis, territorial governance, territorial vision, territorial diversity, vision process.

\section{Introduction: What shapes Europe's future?}

What will Europe look like in a few decades from now? Given current debates about how to best master the challenges Europe faces, incl. a range of responses where Europe hardly plays a role, this is an important question to be asked. It is not only about Europe as a continent or the European Union; it is mainly about European regions and cities.

Discussing possible territorial futures for Europe shows that one easily turns into daydreaming, forgetting about increasing regional disparities which future developments are likely to bring, and thus missing the chance to discuss the actions specifying how to deal with them. Alternatively, discussions about the future may easily take dystopian nature, frequently resulting from uncoordinated actions having no common ground or vision to stand on.

Major changes have been usually the effect of decisions made by policy- and decision-makers in Europe and of exogenous factors such as global decisions or global challenges. A close relationship exists between the internal decisions and externalities. Players at different geographical levels (from local to global) make independent decisions, many of which shape Europe's future. At the same time externalities, such as climate change or changing migration patterns, affect the future development and thus require (re)actions and policy responses at different administrative levels.

Besides vertical structure of the decision-making systems, also the horizontal dimension referring to a wide variety of sector policies and financial resources needs to be considered. Cooperation and relations between different players operating in different sectors (at multiple levels) imply a need for both horizontal coordination between various sectors and vertical coordination between individual 
levels. This also includes involvement of public and private stakeholders representing manifold interests and participation of civil society (Böhme et al. 2015a; European Commission 2015a).

Territorial characteristics and contexts matter for the future development prospects. The above ranges from societal to economic and environmental characteristics being unevenly distributed across Europe. Hence, the impact of external challenges varies between different regions and cities and depends on the specific territorial context: Policy measures addressing climate change differ between coastal and mountainous regions; decision-makers in a metropolitan area with a strong RDTI profile have a different perception of globalisation than their colleagues in an export-oriented region depending on the manufacturing sector. This leads to individual sets of sensitivities which need to be taken into consideration for policy formulation and implementation purposes. When discussing Europe's future it is therefore necessary to better understand Europe's territorial diversity (Böhme et al. 2015a; ESPON 2014a, 2014b, 2014c).

Externalities influence the development options ahead. Decisions made at different levels of governance, in different sectors and territorial settings are influenced by externalities such as existing and new challenges, to which policy formulation and implementation as well as decision-making processes in Europe continuously have to be adjusted. Exogenous factors include, i.a. decisions made at the global level or outside the European Union but also grand societal challenges. Global decisions and decisions made outside Europe matter. This ranges from (geo-)political conflicts e.g. current inflow of asylum seekers and refugees to political decisions such as recent global agreement (COP21) on binding targets to mitigate climate change.

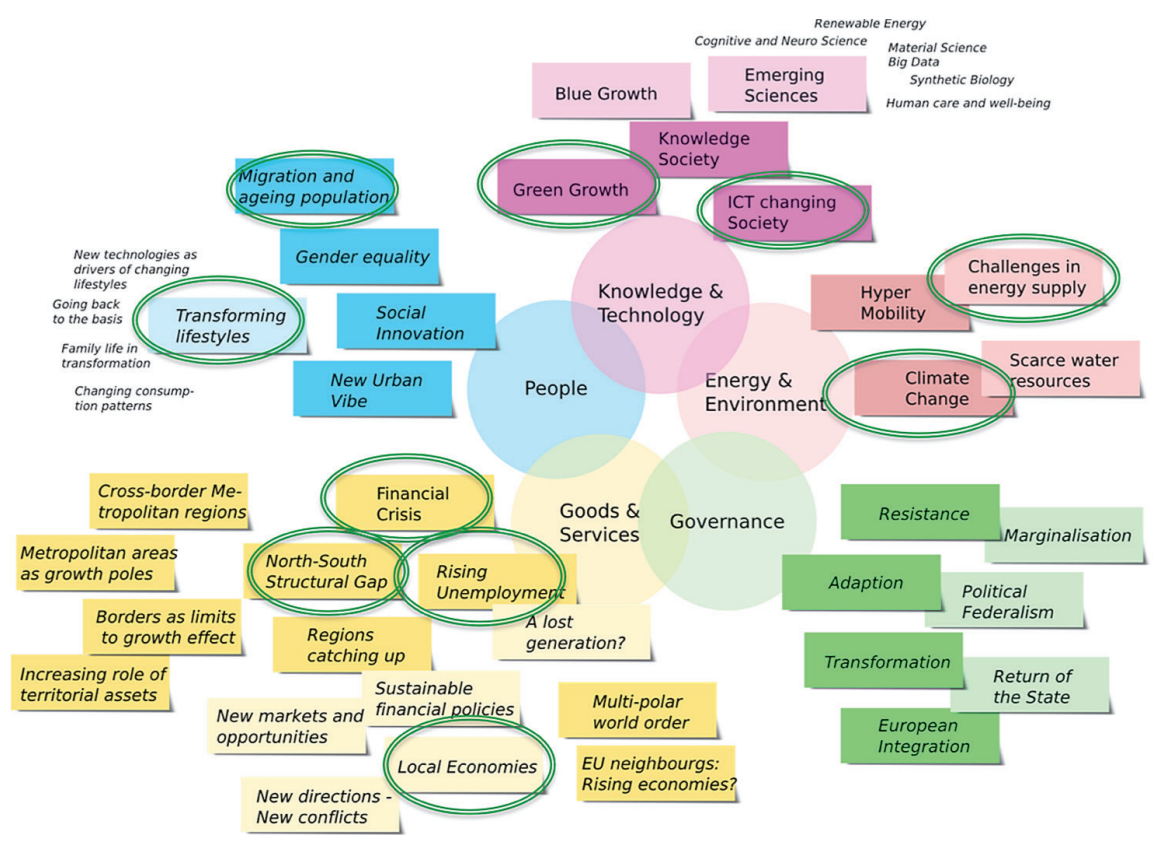

Figure 1. Overview of trends and selection of ten most relevant trends Source: Spatial Foresight for FP7 project FLAGSHIP 2015.

Grand societal challenges will affect future development of European cities and regions. Most prominently, climate change, demographic change, globalisation and the financial crisis can be 
mentioned, however information and communication technologies (ICT), new emerging sciences, energy supply and an increasing structural gap between Northern and Southern Europe are also the trends that shape Europe and pave the ground for its future development path. Territorial development covers many areas, which is why the sections are sub-divided into five themes; (a) Energy \& Environment, (b) Goods and Services, (c) Knowledge \& Technology, (d) People and (e) Governance. The mind map presented in Figure 1 gives the first overview of the identified trends. As economy and particular growth are the main drivers behind the territorial development, trends in 'Goods and Services' theme are dominant in numbers. As seen in the figure, these trends are divided into four groups: (a) Regional Development, (b) Financial trends, (c) Europe in the World and (d) Metropolitan areas. In total, the mind map shows 29 territorial development trends and 7 governance-related trends. The light colouring indicates seeds or wild cards, whereas the dark colouring indicates mega trends with encircled 10 trends considered as being of particular importance.

\section{The FLAGSHIP project}

This article is based on the work conducted for the EU research project Forward Looking Analysis of Grand Societal cHallenges and Innovative Policies (FLAGSHIP) funded under the $7^{\text {th }}$ Framework Programme (FP7). The FLAGSHIP project developed two visions presenting two different pictures of Europe in 2050:

- Perseverance describes a business-as-usual vision. In this vision, policy-making will not underlie clear changes. Instead, global growth will persist as the main paradigm. Despite its conservative nature that will not imply any radical changes, the Perseverance vision assumes that various ambitious targets as defined in the Europe 2020 Strategy (European Commission, 2010) for smart, inclusive and sustainable growth or by sector policies such as the completion of the trans-European transport network (TEN-T), for example, will be achieved by 2050 .

- Metamorphosis, on the other hand, is characterised by two main paradigm changes: Firstly, there will be a shift towards a fully circular economy. This implies revolution in the production and consumption system. Secondly, equality, democracy and participation will act as the main guiding principles for all policies and claimed actively by the population. These paradigm changes will lead to new dynamics and development in all sectors but also affect the decision-making and policy-making processes.

In the next step, the abovementioned trends as well as the current governance system were confronted with key characteristics of the two visions. This led to impact projections that are presented in the following chapters and illustrate how the European territory and governance system in Europe may look like in 2050 under the respective assumptions of the Perseverance and Metamorphosis visions.

At first, the governance dimension will be explored illustrating different governance systems and arrangements for 2050. Afterwards, the territorial dimension will be presented for two thematic fields - Knowledge and Technology, Economic Integration - illustrating different final territorial pictures in these fields in 2050. For both dimensions (cartographic) illustrations are included, which are supposed to function as eye-openers by illustrating the main underlying principles and focusing on key aspects with a strong territorial dimension. These illustrations shall stimulate and enrich discussions. 


\section{Governance dimension}

The FP7 FLAGSHIP project focused mainly on governance arrangements in context of the European Union. However, the changes discussed are actually not necessarily limited to the European Union and may also comprise any other European countries, regions and cities.

\section{Europe on its path towards Perseverance: From Government to Management}

Although the Perseverance is a conservative, i.e. business-as-usual, vision, significant dynamics in governance arrangements will result from progress in different sector policies and imply governance arrangements. Some key characteristics of the future (territorial) governance system are the following:

Territorial governance patterns will be characterised by multilevel governance and subsidiarity. The subsidiarity principle ensures that different remits are assigned to specific administrative and territorial levels, whereas multilevel governance focuses on linkages and interactions between different levels (Böhme et al. 2015b; European Commission 2015a; Faludi 2012).

Due to dominance of governmental players, multilevel governance in the Perseverance Vision can also be described as multilevel government. Formulation and implementation of policies will remain sector-oriented and decision-making, whereas policy interventions will refer to politicoadministrative jurisdictions instead of functional territories. This impedes a specific and integrated focus on territorial matters and development.

The vision furthermore implies that policy will not become pro-active with a focus on long-term strategic approaches but instead remain re-active and be responsive to urgent and short-term challenges and develop and implement ad-hoc solutions. Due to lack of long-term thinking, preliminary consortia and alliances will be established for as long as it is necessary to work together on a specific ad-hoc solution.

Besides these general rationales, the relevance of players from different territorial and administrative levels involved in formulating and implementing policies will change. Shifts in power will be characterised by centralisation - i.e. moving decision making power to supra-national players - and decentralisation processes - i.e. moving decision making power to lower regional or local players. Given the focus of the study on the EU, this implies that - on the one hand - on-going European integration will entail more supranational coordination and harmonisation, i.e. competences will be transferred from the national to the EU level, especially to the European Parliament as main legislative and budgetary and the European Commission as the key executive power.

On the other hand, competences will also be transferred to the local and regional levels. Due to lack of resources at the national level and increasing need for more flexible and place-based arrangements, e.g. in the field of services of general interest, national authorities will continuously withdraw from an increasing number of tasks. Regions and municipalities will furthermore seek to develop and implement region-specific approaches and this way become more autonomous.

Both centralisation and decentralisation process will lead to declining power of national governments. Although they will still have the right to define alternative policies or deviate from European policies and thus remain important players, their overall position will be weaker than today and, consequently, also the influence of the European Council will decrease, whereas the impact of the European Committee of the Regions as representative of municipalities and regions is supposed to increase (Fig. 2). 


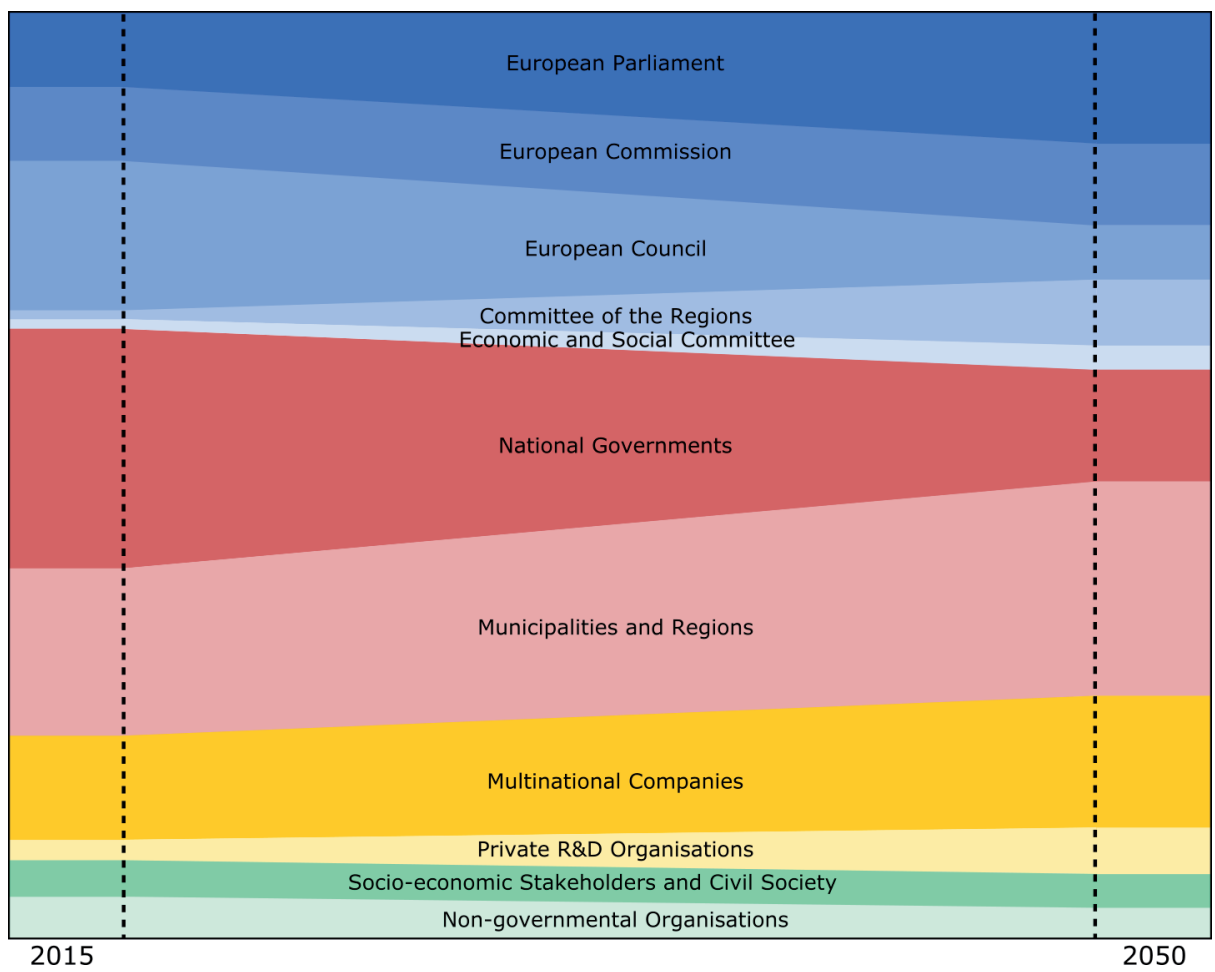

Figure 2. Shifts in power for selected players (Perseverance Vision) Source: Spatial Foresight for FP7 project FLAGSHIP 2015.

\section{Europe on its path towards Metamorphosis: From Places to Flows}

The Metamorphosis Vision is characterised by paradigm changes which will also imply governance arrangements, policy approaches and cooperation between different players and levels.

The main rationale of the Metamorphosis Vision is a drastic change of values and behaviours aiming at possible strategic fit between policies and sustainable development. This sustainability turn will lead to shift from ad-hoc solutions to holistic and systemic approaches. The territorial dimension of different challenges will be considered in formulation and implementation of policy approaches.

Decision-making processes will also change with regard to involvement of different players. New approaches will be tested and new governance players will be involved to consequently lead to establishing new structures of co-decision-making. The relevance of governmental players for decision-making will decline and, in the long run, their 'shadow' will only be visible for formal and legal purposes.

Functional coalitions with a strategic, pro-active and long-term orientation will result from new governance approaches and involvement of new players. Depending on the specific context and challenge, a variety of stakeholders of different scales will be involved which will lead to more flexible geometries of governance and thus also clear delineation of single levels will be replaced with more fuzzy, partially overlapping approaches on flexible scales. This will strengthen the territorial dimension of decision-making and policy implementation. 
These changes in governance arrangements and rationales will have significant implications for the relevance of different players. The aforementioned hybrid understanding of space will not fit with the concept of nation states as independent entities separated by linear borders. Consequently, the relevance of the national level will especially decline which might even lead to disappearance of national level (Fig. 3). In general, the influence of public authorities will decrease as the entire system of public authorities is based on the idea of entities separated by linear borders.

Other players with strong local and regional roots will appear and form place-based coalitions. Constant change of governance structures and processes will occur especially in the early phase of this process, whereas governance will become more fluid because different players can obtain different roles in different contexts. This will lead to various forms of local and regional self-organisation or even self-government. At the European level, these players will be represented by the newly established Local and Regional Councils aiming at replacing the European Council and receiving support from the European Commission. The European citizens will be represented in the European Parliament.

Within a system of overlapping and various fuzzy governance arrangements, cooperation between different local and regional communities will be essential as responsibilities will not always be clearly allocated to a single specific player, community or coalition. More intense cooperation will then lead to deeper integration at various scales ranging from (sub-)local scales to macro-regional or transnational scales and depending mainly on specific context and dimension of a challenge.

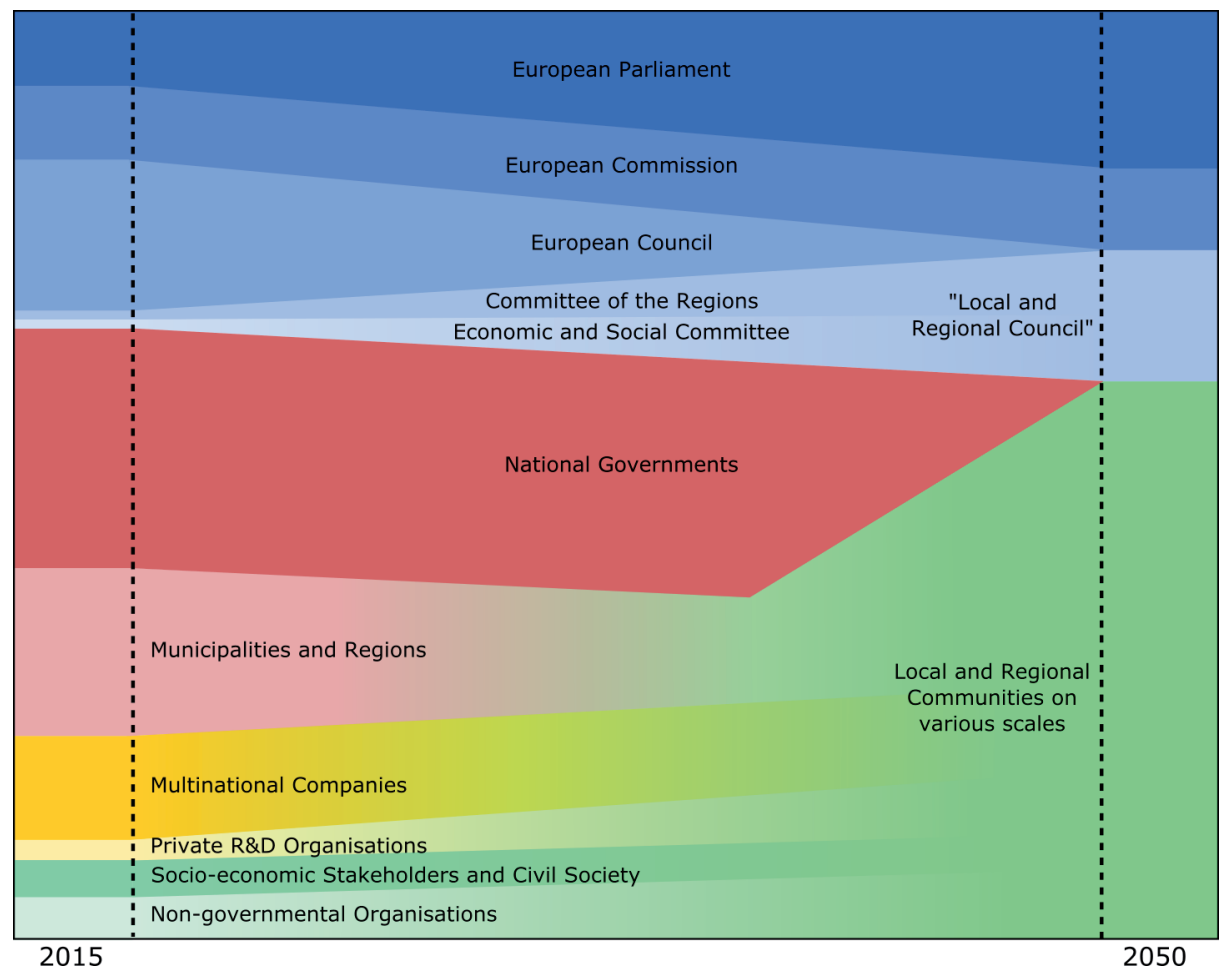

Figure 3. Shifts in power for selected players (Metamorphosis Vision) Source: Spatial Foresight for FP7 project FLAGSHIP 2015. 


\section{More power to the people and supra-national solutions}

Though the two visions are rather different, their overall governance pictures are very much similar. In both visions the role of the nation states declines and more emphasis is given to - on the one hand - local and regional level and civil society and - on the other hand - supra-national, here primarily European-wide decision making processes.

In brief, the emerging future governance systems reflect the shortcomings of our nation state systems as well as shortcomings of the European governance structure and the need for stronger involvement of civil society (Acemoglu \& Robinson 2012; Giddens 2014; Offe 2015).

Decline of the nation states in Europe and emergence of the European society may certainly be deemed as overly optimistic given the current debates about a re-nationalisation of Europe, focusing on finding national rather than European responses to major challenges and putting the national interests first. However the story goes that Europe first needs to experience the limitations and failures of a return to national solutions before understanding and full-heartedly embracing the need for joint European responses based on a shared idea of what Europe is and wants to be.

\section{Territorial dimension of Europe's futures}

Moving from governance dimension to the issue of different territorial impacts, the question is how will Europe develop - in the two visions - with regard to its territorial diversity and territorial cohesion. The mind map of trends presented above provides a number of important starting points to discuss what various trends may imply for Europe's territorial development. In the following lines, we will focus on two of them: (1) knowledge and technology and (2) goods and services / economic integration.

Territorialising the impacts of these two trends for the purposes of these two visions provides first insights what they will mean for different types of territories and different parts of Europe. In methodological terms, the territorialisation was largely implemented by merging approaches of territorial foresight and territorial impact assessment. The territorial impact assessment approach used the one developed by ESPON ARTS (ESPON 2012).

Analysis of the status quo of the European territory was conducted for each thematic field. Based on this, a future picture was developed on the assumptions of the Perseverance and Metamorphosis Visions. In the next step, a number of sector policies were identified as most relevant for the future development in this field. In total, seven working steps with several feedback were conducted to develop an understanding of how the territorial patterns may change and how the territory may look like in 2050, ranging from desk research and literature review to brainstorming sessions and internal workshops to seven regional case studies and expert meetings.

As part of the abovementioned drafting process of the territorial future, two illustrative maps were developed for each thematic field to display the territorial dimension of individual fields under the assumptions of the Perseverance and Metamorphosis Visions. The purpose of these maps is threefold: (1) To illustrate the general underlying principle and help to understand the basic idea of the territorial dimension; (2) To display key aspects with a strong territorial dimension and highlight differences between the territorial dimensions of the two visions; (3) To stimulate and enrich discussions: a picture is worth a thousand words. 
The maps are not meant as accurate illustrations of the future but rather as eye-opener showing possible territorial diversities that future might bring. Contrasting the results for the two different visions provides insights on the range of possible territorial implications.

\section{Territorial dimension of Knowledge and Technology}

Information and Communication Technologies (ICT) will play an important role for social and economic development in the Perseverance Vision. The Internet of Things and Everything and a data-driven economy will act as the key elements in the Perseverance Vision and be paramount for all sectors related to society and economy. As the use of ICT depends primarily on access to ICT, it will rely on the quality of access to high-speed networks. Given the current policies, it can be expected however that access to ICT will be distributed unevenly across Europe. Access to the cutting-edge and most recent technologies will hence be restricted to the main European metropolises, which will entail comparative advantages for these regions and lead to an increasing gap between urban and rural, peripheral and sparsely populated regions. This will conduct to even stronger position of urban poles and allow them to further develop their role as growth engines (Fig. 4). Only in the regions with high density of urban areas, the potential for synergies and integration between metropolitan areas and their surroundings will be developed. The remaining rural regions will be mostly detached from new technological developments (ESPON 2013a; De Prato \& Nepelski 2014).

These changes will significantly affect education and science and, consequently, Research, Technology, Development and Innovation (RTDI). The quality and structures of education and training will differ between urban and rural areas and the most important research institutions and organisation will concentrate in the main urban agglomerations providing the best access to ICT. Synergies and spill-over effects will be however restricted to areas in a close proximity to agglomerations.

As the advanced ICT access generally leads to better results in educational and academic achievements, demand for related skills will increase and the regions with better access will produce more highly skilled labour force to further develop the data-driven economy. Concentration of technology and research institutions will therefore also cover people, capital and enterprises, whereas the other primarily rural areas will more frequently experience continuous brain drain and outflow of human capital.

Other fields offering substantial potential for future economic activities include green growth and technology, and blue growth and technology, respectively. Both approaches link sustainability and environment-friendly economic growth and innovation. Green growth and technology refers to territorial assets, blue growth and technology to marine potential and resources. (ESPON 2013b; Zillmer et al. 2014) Due to their focus on ecological resources, both fields generally offer economic potential for rural areas. However, as human capital and technologies will be rather concentrated in urban areas, the green and blue economy will become more important in agglomeration areas than in rural and coastal (and other marine) regions. Rural and coastal regions will mainly provide natural assets and environmental resources, but the main economic activities offering high value-added will rather take place in agglomeration areas. 


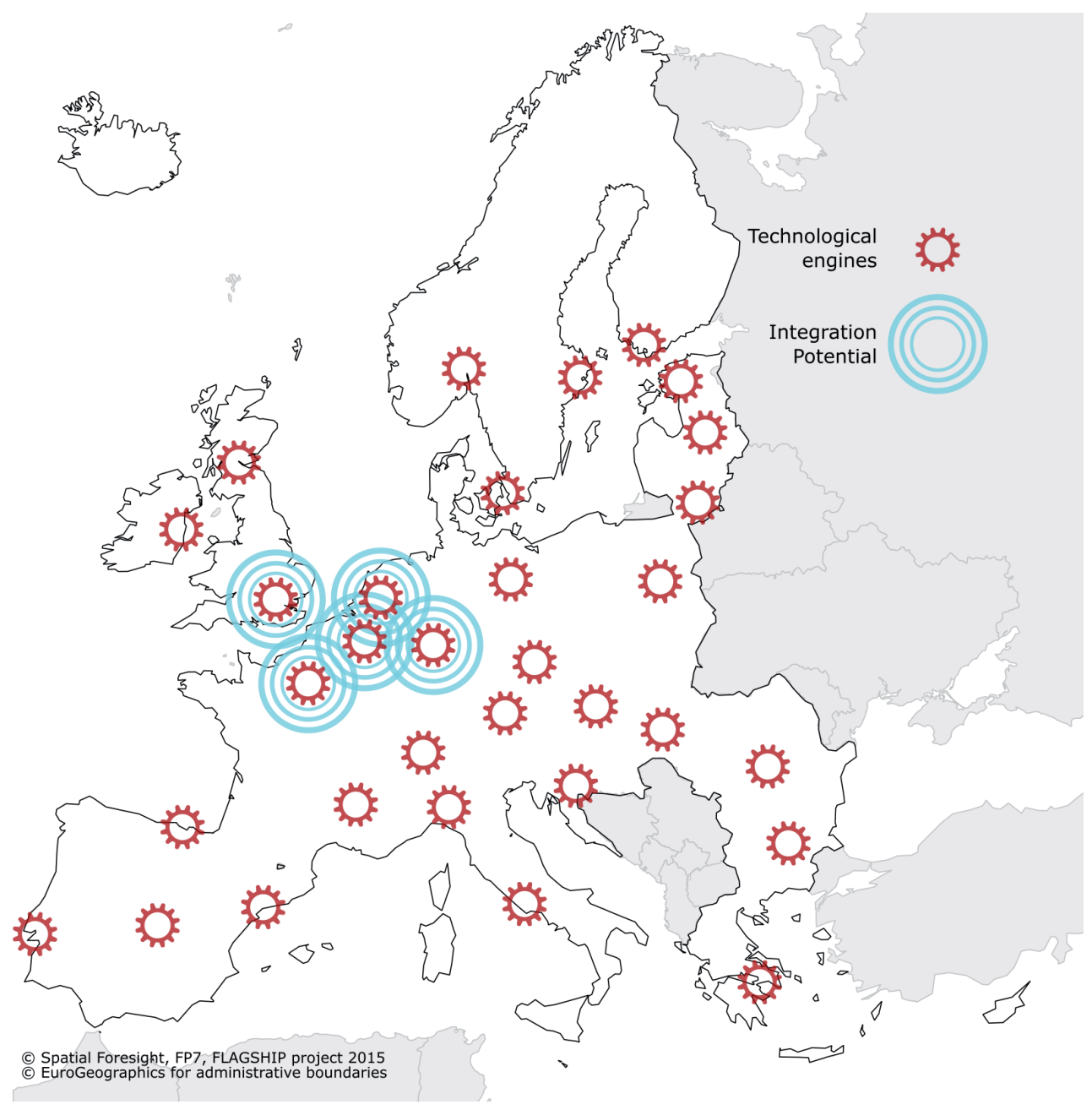

Figure 4. Knowledge and Technology in 2050 (Perseverance Vision) Source: Spatial Foresight for FP7 project FLAGSHIP 2015.

Also in the Metamorphosis Vision, ICT will be paramount for socio-economic development. In contrast to the Perseverance Vision however, the access to ICT will be more evenly distributed across the European territory. The distinction between providers and users of ICT will continue to disappear. It can be seen already today that people do not only consume but also produce content. In future, this will also apply to the infrastructure side. Dependency on stationary and large-scale physical infrastructure will be replaced with networks in which all individual devices are nodes that boost the signal. Hence the users will become providers and build the network conjointly. If ICT access is available ubiquitously, technological development and innovation will appear in different places and new development opportunities will emerge especially for rural and peripheral regions.

The new way of using and accessing ICT will also change science. Networks of scientists and researchers will become location-independent and replace major universities and research centres as RDTI hubs. Social capital will consequently be distributed more evenly and promote endogenous 
and balanced territorial development. Based on a combination of cooperation and competition (co-opetition), the regions will develop different profiles and adjust the new technologies and innovations to their specific needs and context. This combination of cooperation and competition will also lead to integration processes, which will take place on different scales - from intra-regional to inter-regional scale and beyond (Fig. 5).

The new way will furthermore affect the educational systems. General level of education will increase and, due to better access to new technologies, skills and capabilities fitting the needs of specific regions or a specific regional system will become more important than formal educational attainments, for example. As everybody has a value in such a complex system, the main challenge is to find the place where a specific person is able to contribute to societal development in the best way. This of course implies additional challenges, e.g. how to bridge physical and psychological distances.

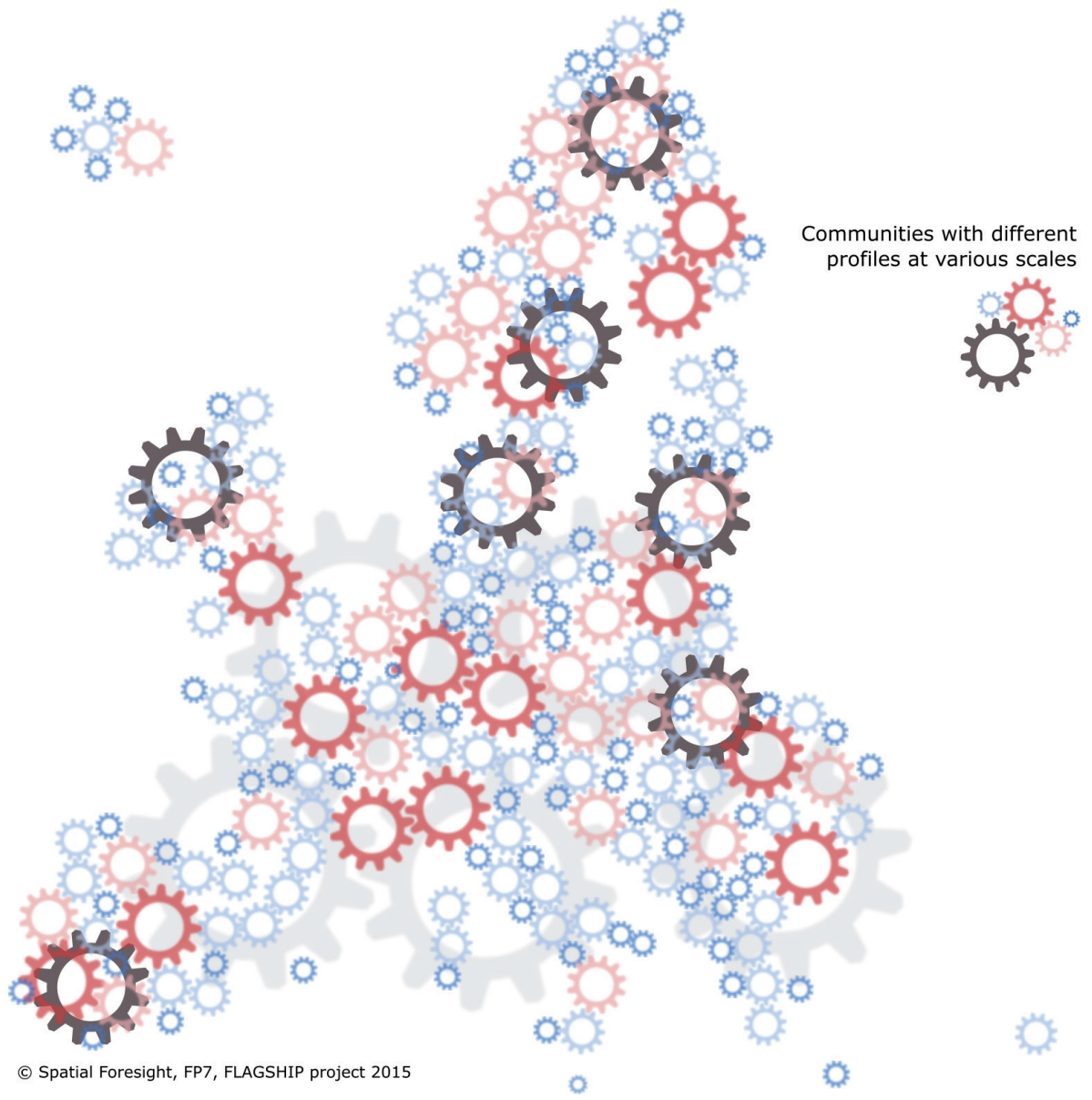

Figure 5. Knowledge and Technology in 2050 (Metamorphosis Vision) Source: Spatial Foresight for FP7 project FLAGSHIP 2015. 
Due to the paradigm shift towards a full-circular economy, economic growth will be decoupled from resource consumption, which is of course a comprehensive challenge that needs new ideas and ways of thinking. (Ellen MacArthur Foundation et al. 2015; European Commission 2015b) As regions that already today show good performance in the field of sustainable development and green growth might be inclined to retain their chosen path, this will allow less developed but innovative regions to catch up to the leading regions. This development requires however functioning public institutions, general and financial support and access to innovations, skills and knowledge.

The two different visions show that territorial implications of knowledge and technology trends vary substantially. Developments hold actually the potential to contribute to territorial cohesion and more balanced development potentials concerning the access and use of knowledge and technology infrastructures and services. At the same time, depending on the pathway chosen, it might equally well imply an increasing focus on specific hubs resulting in increasing territorial disparities. All in all, territorial impacts will depend on the prevailing technical solutions and governance of infrastructure and service provision.

\section{Territorial dimension of economic integration}

In the conservative Perseverance Vision, economic development in Europe will be influenced by both centripetal and centrifugal forces. This will reinforce concentration processes and the core-periphery pattern. (Böhme et al. 2015a; Lüer et al. 2014)

On the one hand, economic integration will take place at different levels, e.g. across the former Iron Curtain at the German-Polish border area (Berlin-Szczecin-Poznan), at the Baltic Sea (HelsinkiStockholm-Tallinn) region or at the Austrian-Slovakian-Hungarian border (Vienna-Bratislava-Györ). This will lead to on-going integration of the European core, comprising Germany, France, the Benelux, Scandinavia and certain countries in eastern and northeast Europe (Fig. 6).

On the other hand, centrifugal forces will challenge the integration process. This includes, among others, the trend of (economic) renationalisation that refers to departing from the European Union and establishing closer links with other regions of the world, for example with former colonies that are expected to grow significantly in the next decades (e.g. Portugal, Brazil, Angola and Mozambique) or any other countries with which they have long-standing relationships (e.g. United Kingdom and Ireland, USA and Canada). In addition, other conflicts in the European neighbourhood will also have a significant impact on future development and (economic) integration in the European Union, e.g. in Turkey, Ukraine and Middle East. Whether or not it will be possible to solve these conflicts will certainly reinforce either centripetal or centrifugal forces.

With regard to the latest financial crisis that has especially affected Ireland, Spain, Portugal, Cyprus and Greece, significant social and economic tensions can and will be seen for the next 5-10 years. However, in the long-term perspective it can be expected that these regions will attract people again after a long and steep decline. This may lead to a new hype, which can also cause a new bubble burst within a few years. Smart specialisation strategies will play a crucial role in avoiding this and basing future economic development on the existing regional strengths. As smart specialisation relies on the empowerment and involvement of regional and local players, their expertise and creativity, it will be paramount that the European and national levels create a functioning institutional, financial and legal environment enabling these players to exploit their potential and actively develop and implement such strategies.

With regard to Europe's embeddedness in international flows of goods, maritime transport and logistics are playing an important role. Also in 2050 , both outflow and inflow of goods will continue 
to rely on the motorways of the sea. Due to continuous concentration processes in the European core, the ports of the North Range in Belgium (Zeebrugge, Antwerp), the Netherlands (Rotterdam, Amsterdam) and Germany (Hamburg, Bremerhaven) will focus on further development of their capacities. As the Mediterranean ports however offer faster connections to the Far East, they also offer enormous potential for future development. Establish sufficient hinterland connections which are so far less developed than in northwest Europe will be here of particular importance.

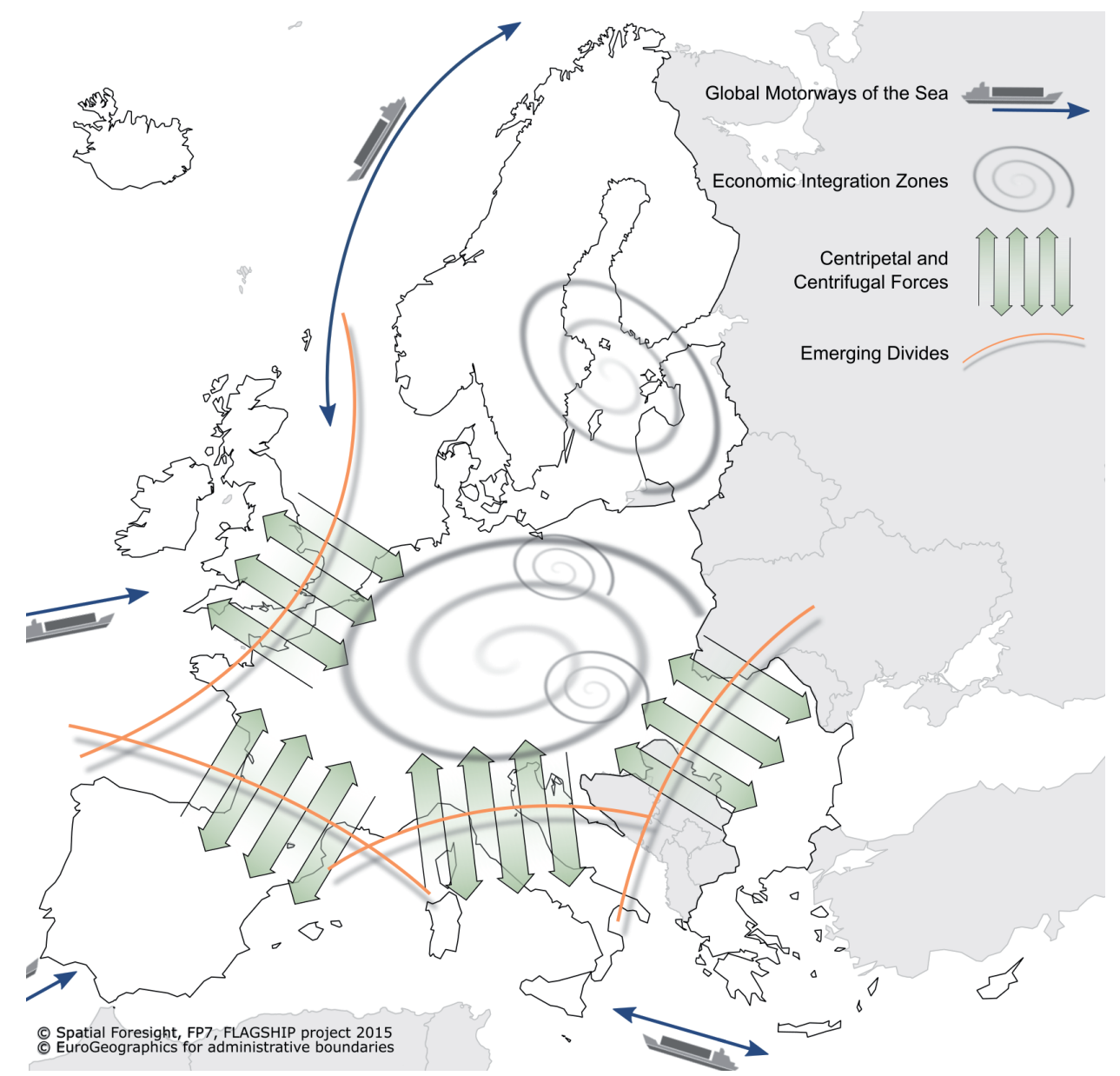

Figure 6. Economic integration in 2050 (Perseverance Vision)

Source: Spatial Foresight for FP7 project FLAGSHIP 2015.

A paradigm shift in consumption will entail radical changes in this area in the Metamorphosis Vision. Mass consumption will be replaced by ecologically and socially responsible one. Although many products and services will be produced and provided on local and regional level, they will also be exchanged between different regions. This will lead to establishing an economic system of interacting and trading, yet equal regions. 
This new approach for economic cooperation will lead to functional and institutional integration on different scales, ranging from cross-border to macro-regional scales (Fig. 7). Better cooperation is then expected to promote polycentric development and territorial cohesion in Europe.

Due to a generally high degree of (cross-border) integration, national borders will no longer matter by 2050 in the Metamorphosis Vision. However, as different cross-border regions are at different stages of their integration process, they first have to focus on different aspects to foster integration, ranging from the development and implementation of solutions for political and ethnical conflicts as well as promotion of linguistic skills to develop joint technical and social infrastructures and enhance institutional cooperation.

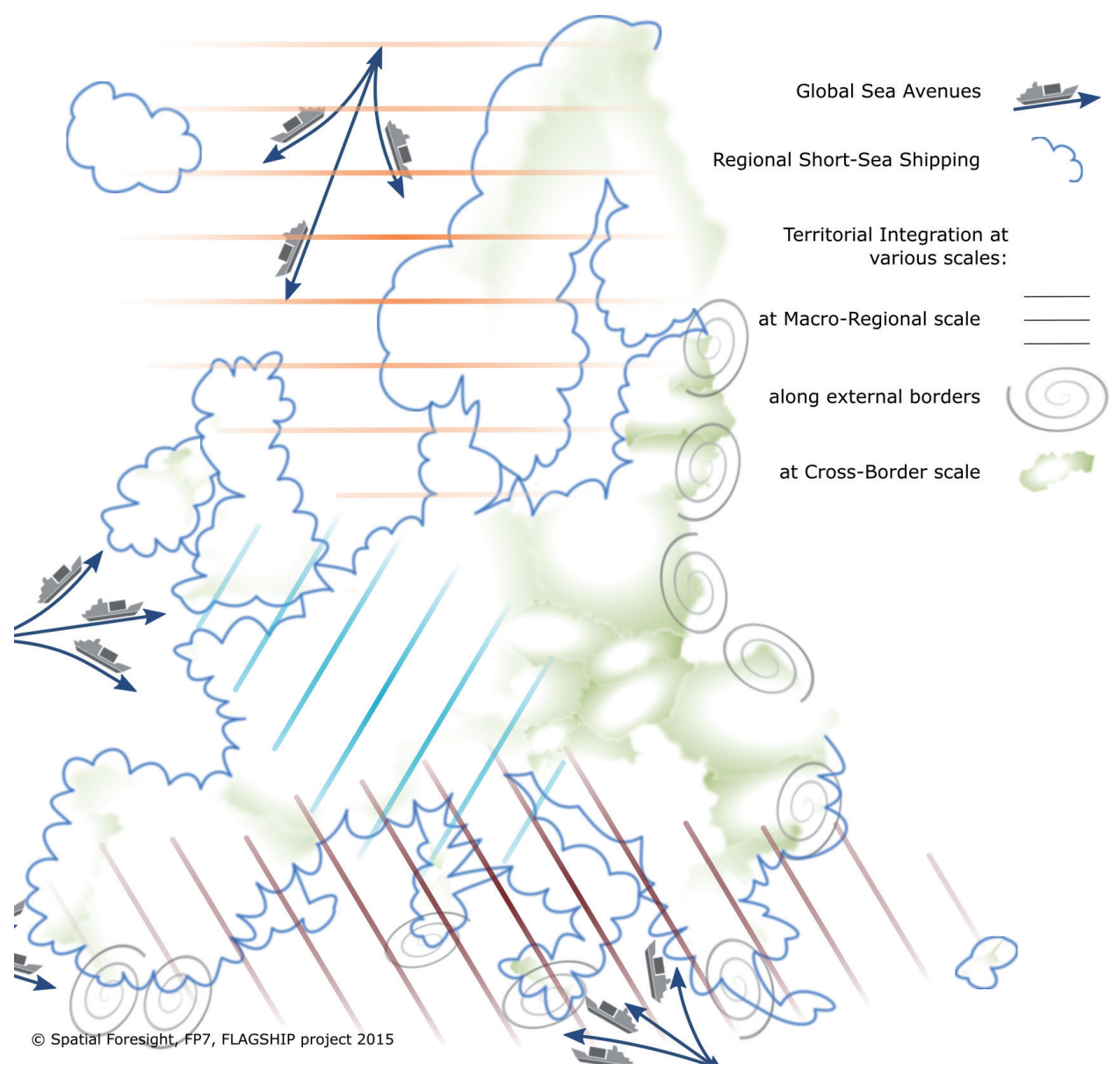

Figure 7. Economic integration in 2050 (Metamorphosis Vision)

Source: Spatial Foresight for FP7 project FLAGSHIP 2015.

Regional development will have more extensive range and allow for various development paths. Based on local knowledge, open-ended entrepreneurial experimentation will lead to discovery processes on a microscale. This adds a new component to smart specialisation, because the regional scale only steps in afterwards to further develop the specialisation and ensure continuing participa- 
tion of the micro-level players. Based on this small-scale approach, each region will develop an individual profile, leading to new economic patterns and new forms of intra- and inter-regional economic integration.

For micro-scale experimentation and its utilisation, a high level of institutional capacity is essential. As some regions will lack the institutional capacity at the beginning, they offer good preconditions for alternative and more ventured local and regional approaches. These regions rely however on support and empowerment from the European and macro-regional scale to develop their own local (institutional) capacity.

With regard to maritime transport, the relevance of point-to-point connections and short-sea shipping will increase. The old system with a number of dominating maritime hubs at the North Sea does not fit into the new economic system. Instead a decentralised system of smaller ports will emerge. When it comes to hinterland connections, a shift from road to inland waterways will lead to a better-integrated transport system.

Taken together, both these two different Visions emphasise the role of some sort of macroregional contexts in terms of economic integration. While the Perseverance Vision plays strongly on centripetal and centrifugal powers developing into some sort of ever deeper integrating core Europe with various fringes around it, the Metamorphosis Vision focuses on larger integration zones complemented by increasing integration along the national borders, in particular in Central and Eastern Europe.

\section{Wild cards}

Based on a set of assumptions, the Perseverance and Metamorphosis Visions show two different futures for 2050. The developments described in these visions and their assumptions are however not certain to happen. On the contrary, it might be more likely that several unexpected events will have enormous implications and lead to different development path for the next decades (Steinmüller \& Steinmüller 2003). Events of low likelihood but high impact have influenced Europe's development in the past. Therefore it is quite probable that these 'wild cards' will continue to change the game in the future. Their wildness might differ considerably and mainly depends on the reader's imaginative power. Selected wild cards elaborated by the FLAGSHIP project are presented below, mainly with the aim to provoke thinking about the unexpected:

Grey slums. At the global level, urbanisation is currently driven by poverty. Population surplus is not required for the economy and society and thus expelled. Given the ageing process in the EU, the question is whether the pensioners will become Europe's surplus and inhabitants of 'grey slums'.

No more EU. Financial or the refugee crises show the increasing dissent between the EU Member States. In future, this might lead to voluntary and forced exists and to the collapse of the EU in the mid-term perspective.

No more EU Cohesion Policy. Following today's economic argumentation, single projects, investments and sector policies are more efficient than comprehensive regional policies. EU Member States will therefore reduce the European budget 2020+ and abolish cohesion policy in 2028.

Privatisation of EU Commission Services. Already today the European institutions outsource a considerable share of their back office functions. In future, the EU Member States might decide to outsource all Commission services to private tenderers, e.g. the Big Four.

No more Digital. Due to a number of incidents, people loose trust in ICT and new technologies and choose to work and communicate offline. Only the online nerds that are able to access the Internet in secure manner will use online services and continue to communicate online. 
The Europeans go South and East. Europe is an old continent with ageing population. Other regions, especially in Africa and Asia, will become booming economic centres that continuously attract young talents from Europe.

Emergence of new states. Catalonia, the Basque Country, Scotland, Wales, Northern Ireland, South Tyrol, Bavaria and Flanders will vote for their independence in referenda. Many of these new states will remain in the EU and significantly change the power structures of the EU and its institutions.

Russia joins the EU. Despite current conflicts (e.g. Ukraine, Syria), economic integration between the EU and Russia will continue. Similar to the Trans-Pacific Partnership, the EU and Russia will sign a pan-European partnership, establish a single market and become a regular member state of the EU.

\section{Conclusions}

Although the described visions differ in many points, the basic picture is similar: Both visions entail more subsidiarity and a stronger role of local and regional governance players, and at the same time more power at the European level. This combination of centralisation and decentralisation reflects the need to develop place-based approaches to address region-specific challenges as well as continuous withdrawal at the national level from an increasing number of tasks in the field of services of general interest. However, the approaches to be developed vary significantly in detail and can thus either reinforce or counterbalance the specific challenge. By doing so, these can lead to increasing territorial disparities or more balanced, polycentric development.

The above underlines the interdependencies between emerging trends, territorial development and governance patterns on the one hand, but also reveals uncertainties and that the ultimate impact of a specific approach depends on its precise design. Furthermore, it illustrates that visions need actions and vice versa:

Visions without actions are daydreams. Knowledge about the picture of a desirable future is meaningless if the decision-makers and other players have no understanding or imagination how they can implement single actions necessary to realise this future.

Actions without visions risk to become nightmares. If the decision-makers have a wide understanding of different unrelated short-term actions, policy formulation and implementation will become chaotic. People in the driver's seat need to have a common idea, say a compass that provides them with orientation and guides them.

\section{Europe needs a joint vision process}

Given the current developments in Europe, there is a need for a shared vision - a vision shared across countries and levels of society, which helps understanding why the Europeans need to find common answers to today's challenges.

Political journalists and analysts as well as former political leaders comment frequently that today's leaders in Europe lack a joint vision and that neither they nor citizens do know (anymore) what Europe is or should be standing for. However, such a vision needs to be shared broadly and involve all relevant players in the development process, e.g. through a co-design strategy. Interaction, consisting of co-designing a commonly owned new development path seems the core activity of players in the creative decision-making process for strategic planning (Vogelij 2015).

For approaching such a vision process, some key aspects need to be taken into consideration (Zillmer et al. 2015: 33): 
Preparation. Here it is crucial to set up large participative processes to involve various players and acquire their support. Long-term support and commitment is furthermore important for the key players initiating a vision process. In order to avoid excessively wide scope, the process should focus on one (commonly agreed) vision that can even be restricted to a single specific topic.

Presentation. It is important that all involved players conjointly develop the vision and perceive it as 'their' vision. Hence, measures to create ownership are necessary. In terms of timing, presentation of the final result of the visioning process should be related to other decision-making processes so that the usefulness and relevance for other processes can be illustrated. In order to strengthen the territorial dimension, maps or cartographic illustrations could be used as suitable tools for presentation but understanding and interpreting them may prove to be challenging for policy-makers.

Awareness raising. Vision processes do not only raise awareness about what is actually shared between different players but also emphasises which aspects are not shared. In order to promote polycentric and balanced territorial development, it is important to clarify and raise awareness for the territorial dimension of the vision. Does the vision take into consideration the territorial diversity of the area in question?

Type of discussion. A vision process is not the right tool for any kind of discussion. It can stimulate a broader debate on common objectives as it allows the involved players to develop a common understanding of what the future territory shall look like. However, the picture of the territorial future should not be an end in itself. It is furthermore important that the exercise serves a more general objective and is linked to an overarching goal or decision-making process (see above).

Added value. Vision processes and territorial visions have a high added value for overarching policies as they provide orientation and function as a compass. The result of a vision process can be a common framework to guide other policies or initiatives.

Still, one needs to keep in mind: a vision (however good) without action remains a daydream, while action without a vision easily can turn into a nightmare. In that sense it really seems like Europe's territorial future lies between daydreams and nightmares right now.

\section{Pointers for EU Cohesion Policy}

Besides the particular need for a vision process, the territorial and governance implications of the Perseverance and Metamorphosis Visions also raise a number of questions relating to the future of various policy fields at any level of governance. Whereas most policy fields are addressed in one way or the other by this, it is most prominently the case of EU Cohesion Policy. Consequently, a few pointers for EU Cohesion Policy are presented. Each pointer concludes with a question to stimulate the discussion and enrich the debate about the future of Cohesion Policy 2020+.

Binding local and European responses. The visions show that increasing diversity, disparities and stronger local governance levels need to be balanced by a larger territorial sense of belonging and identity. As small single territories are not viable, there is a need to keep Europe together and implement an approach to solidarity despite an increased focus on place-based solutions. How can Cohesion Policy be strengthened to build that bridge between supporting both more place-based responses to societal challenges and a stronger European solidarity and identity?

European-wide investment programmes. The nation state is getting weaker and the decisions about future infrastructure and technological networks need to be increasingly made at the European level. Indeed, these networks may increasingly become truly European networks rather than merely a patchwork of national networks. Can national and regional programmes address these changes 
and new needs appropriately, or is there rather a need for European-wide or stronger transnational investment programmes?

Community-Led Local Development. The expected increasing territorial diversity of answers to grand societal challenges implies that local and regional players as well as civil society are important game changers. Lower levels of governance are becoming stronger and need to take responsibility for finding truly place-based answers to grand societal challenges as there is no one-size-fits-all solution. In many cases this implies that these stakeholders need to be equipped with the capacities to do so. Can national and regional programmes address these changes and new needs appropriately, or is there a need to break programmes down into more small-scale initiatives (e.g. putting more emphasis on the Community-Led Local Development tool)?

Thematic objectives. The visions show that in translating Europe's grand societal challenges into regional development issues, there are six major areas that need to be addressed. These are the (a) responses to demographic change, (b) responses to climate change, (c) the need to find new economic and societal models, (d) energy production, consumption and networks, (e) ICT developments, applications and networks, and (f) new transport solutions and networks. How can Cohesion Policy contribute in these fields to approach simultaneously both new solutions for European-wide frameworks and place-based solutions for actual implementation?

Encouraging experimental developments. The visions show that there is no clear answer when it comes to future socio-economic development, while also highlighting local and regional applications of, and adaptation to, the new technological trends. Indeed, taken together with the territorial and governance implications of grand societal challenges, there will be a plurality of responses of an increasing diversity. This also implies that different areas and players need to test and approach different solutions, including preparing for the risk of setbacks. How can an increasingly risk-adverse Cohesion Policy encourage experimental developments towards new societal and economic solutions?

\section{Acknowledgements}

This article is based on the work conducted for the Forward Looking Analysis of Grand Societal cHallenges and Innovative Policies (FLAGSHIP) project, funded from the European Union under the $7^{\text {th }}$ Framework Programme (FP7). The project was carried out from January 2013 to December 2015 by a consortium led by the Istituto di Studi per I'Integrazione dei Sistemi (ISINNOVA, Rome, Italy). Spatial Foresight managed the work package on territorial governance.

\section{References}

Acemoglu D., Robinson J.A., 2012. Why nations fail: the origins of power, prosperity, and poverty, 1. New York: Crown Publication.

Böhme K., Holstein F., Toptsidou M., 2015a. Report on the Assessment of Territorial Cohesion and the Territorial Agenda 2020 of the European Union. Luxembourg: Luxembourg ministry of sustainable development and infrastructures on behalf of the EU Trio Presidency.

Böhme K., Zillmer S., Toptsidou M., Holstein F., 2015b. Territorial Governance and Cohesion Policy. Study. IP/B/REGI/IC/2015-095. July 2015. Brussels.

De Prato G., Nepelski D., 2014. Mapping the European ICT Poles of Excellence. The Atlas of ICT activity in Europe. 
Ellen MacArthur Foundation, McKinsey Centre for Business and Environment, Stiftungsfonds für Umweltökonomie und Nachhaltigkeit, 2015. Growth within: a circular economy vision for a competitive Europe.

ESPON, 2012. ARTS. Assessment of Regional and Territorial Sensitivity. Final Report. Version $30 / 07 / 2012$.

ESPON, 2014a. Territories finding a New Momentum: Evidence for Policy Development, Growth and Investment. (No. 3), ESPON Synthesis Report. Luxembourg: ESPON.

ESPON, 2014b. ESPON Atlas. Mapping European Territorial Structures and Dynamics. Luxembourg. ESPON, 2014c. ET2050. Territorial Scenarios and Visions for Europe. Final Report. Luxembourg: ESPON.

ESPON, 2013a. Territorial Dynamics in Europe: Gateway Functions in Cities, Territorial Observation. Luxembourg: ESPON.

ESPON, 2013b. GREECO. Territorial Potentials for a Greener Economy. (Draft) Final Report. Version 30/05/2014. Vol. 1. Main Report. Luxembourg: ESPON.

European Commission, 2015a. Local and Regional Partners Contributing to Europe 2020: Multi-level governance in support of Europe 2020. Brussels.

European Commission, 2015b. Communication from the Commission to the European Parliament, the Council, the European Economic and Social Committee and to the Committee of the Regions. Closing the loop - An EU action plan for the Circular Economy.

European Commission, 2010. Communication from the Commission to the Council. EUROPE 2020. A strategy for smart, sustainable and inclusive growth. Luxembourg.

Faludi A., 2012. Multi-Level (Territorial) Governance: Three Criticisms. Planning Theory and Practice 13, pp. 197-211.

Giddens A., 2014. Turbulent and mighty continent: what future for Europe? Cambridge: Polity Press.

Lüer C., Toptsidou M., Zillmer S., 2014. Calculating regionalised scenarios meeting Europe 2020 objectives [in:] ESPON (ed.), Science in Support of European Territorial Development and Cohesion, ESPON 2013 Scientific Report. Luxembourg: ESPON, pp. 164-168.

Offe C., 2015. Europe entrapped. Cambridge, Malden: Polity.

Steinmüller A., Steinmüller K., 2003. Ungezähmte Zukunft : wild cards und die Grenzen der Berechenbarkeit. München: Gerling Akademie Verlag.

Vogelij J., 2015. Effective strategy making. Co-designing scenarios as a tool for effective strategic planning. Delft: Delft University of Technology.

Zillmer S., Böhme K., Lüer C., 2015. Territorial Scenarios and Visions of Europe for 2050: Proceedings of the Workhop of the incoming Luxembourg EU Presidency on 23 April 2015. Heisdorf: Spatial Foresight.

Zillmer S., Lüer C., Toptsidou M., 2014. Transnational perspectives for green and blue growth. How municipalities and regions can promote sustainable growth and use marine resources in the context of INTERREG IV B. BBSR Special Publications.

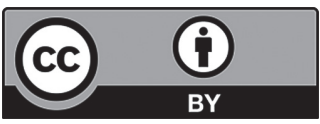

